\title{
PNEUMATIC SUPPORTING OF THE PRECISE FINE OIL SEED GRINDING PROCESS
}

\author{
K. Tyszczuk ${ }^{*}$, K. Peszyński ${ }^{* *}$, A. Mroziński ${ }^{* * *}$, G. Śmigielski $^{\dagger}$
}

\begin{abstract}
The results of the tests relating to the pneumatic transport process in a shredder making it possible to reach the optimum efficiency and quality of the product constituting the basis for biological diet supplements, are presented in the article. Experimental studies were conducted consisting in the evaluation of the flow losses in individual sections of the pneumatic transport. The system in the form of the transfer function considering the air flow without the shredded material has been described.
\end{abstract}

Keywords: flow rate, precise shredder, transfer function, measurement and control system

\section{Introduction}

Precise grinding of fine seeds with high oil content (for ex. brown and golden flax seeds, sunflower, chia seeds, black cumin, mustard) has to be conducted without a significant temperature increase after grinding. That requirement is connected directly with an organic seed content. Plant organisms comprise many different secondary metabolites, which constitute a source of pharmacological active compounds used both as medicaments as well as nutraceutics. The unique properties of nutraceutics determine the biologically active substances demonstrating strengthening, weakening or modifying functions of an organism. Due to this fact, studies are being conducted on the process and design dies supplementation supporting, where the process of seeds grinding drives them to optimum grinding in the aspect of digestibility and without a temperature increase (Tyszczuk, et al., 2009). The technological system of fine seed grinding with a precise shredder RPW is shown in Fig. 1.

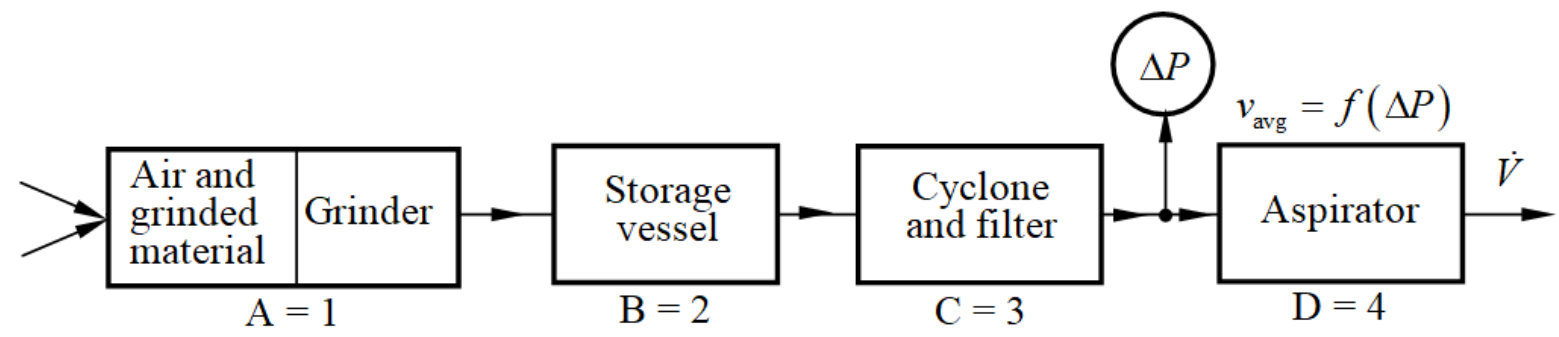

Fig. 1: Division of the technological line into measuring sections.

The accepted mechatronic solutions, as well as looking for new ones, are based on numerous process simulation studies, analyses and methodology of control and the CAD construction modelling environment (Macko, et al. 2017), (Czerniak, et. al., 2015), (Pecháč, et. al., 2016). The pneumatic

\footnotetext{
Assoc. Prof . Krzysztof Tyszczuk, PhD.: Faculty of Mathematics, Physics \& Technical Science, Kazimierz Wielki University in Bydgoszcz, ul. J.K.Chodkiewicza 30, 85-064 Bydgoszcz: PL, krzytsz@ukw.edu.pl

** Assoc. prof. Kazimierz Peszyński: Wydział Inzynierii Mechanicznej,Uniwersytet Technologiczno-Przyrodniczy; Al. prof. S. Kaliskiego 7; 85-796 Bydgoszcz: PL, kazimierz.peszyński@utp.edu.pl

*** Assoc. Prof. Adam Mroziński, PhD.: Wydział Inzynierii Mechanicznej,Uniwersytet Technologiczno-Przyrodniczy; Al. prof. S. Kaliskiego 7; 85-796 Bydgoszcz: PL, adam.mrozinski @utp.edu.pl

$\dagger \quad$ Assoc. Prof . Grzegorz Śmigielski, PhD.: Faculty of Mathematics, Physics \& Technical Science, Kazimierz Wielki University in Bydgoszcz, ul. J.K.Chodkiewicza 30, 85-064 Bydgoszcz: PL, gs@ukw.edu.pl
} 
transport is an essential element in the process of precise grinding with a RPW shredder (Tyszczuk et. al., 2009). Its role consists in the transport of the material to the operating part and its quick and effective removal from the sphere. The grinding time is of seconds, there does not occur any increase of the temperature of the shredded material. It makes it possible to preserve the properties and qualities of the shredded material on the raw material level.

The complete precise grinding testing line is shown in Fig. 2.

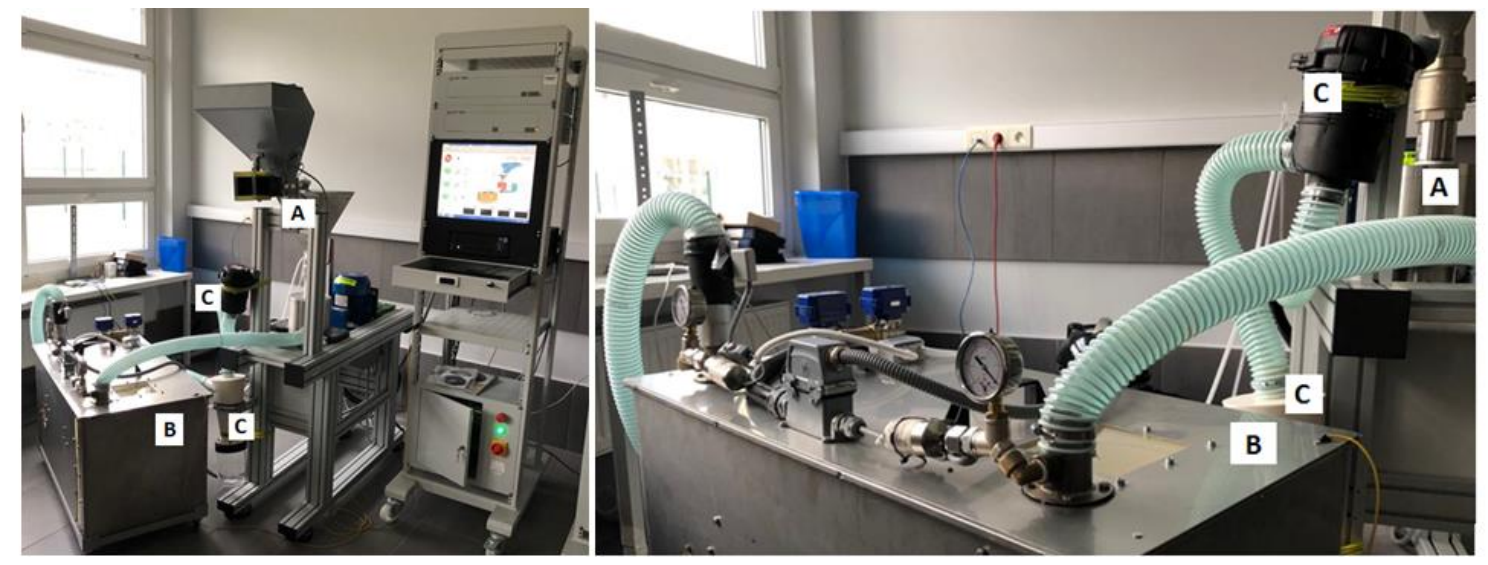

Fig. 2: View of the test stand of precise seed grinding with pneumatic transport. A-grinder, $B$-storage vessel, $C$-cyclone and filter, $D$-aspirator.

In the case of an excessive air flow speed, there may occur a loss of the finest shredded material fractions, what shall be observed in the control cyclone. Control elements, i.e. the flow meter, vacuum meters and the Prandtl pipe, everything with digital measurement converters, have been applied in the test stand in order to recognize the pneumatic transport phenomenon. A computer application making it possible to control the performing devices and to visualize the process variables has been developed in the LabVIEW environment (Fig. 3). There are being conducted studies aiming at the determination of the volume of subatmospheric pressure and the flow speed in the individual sections of the technological line. The mathematical model considering the specificity of the pneumatic system in precise grinding has been developed as the first phase of the works (Tyszczuk, et. al., 2017).

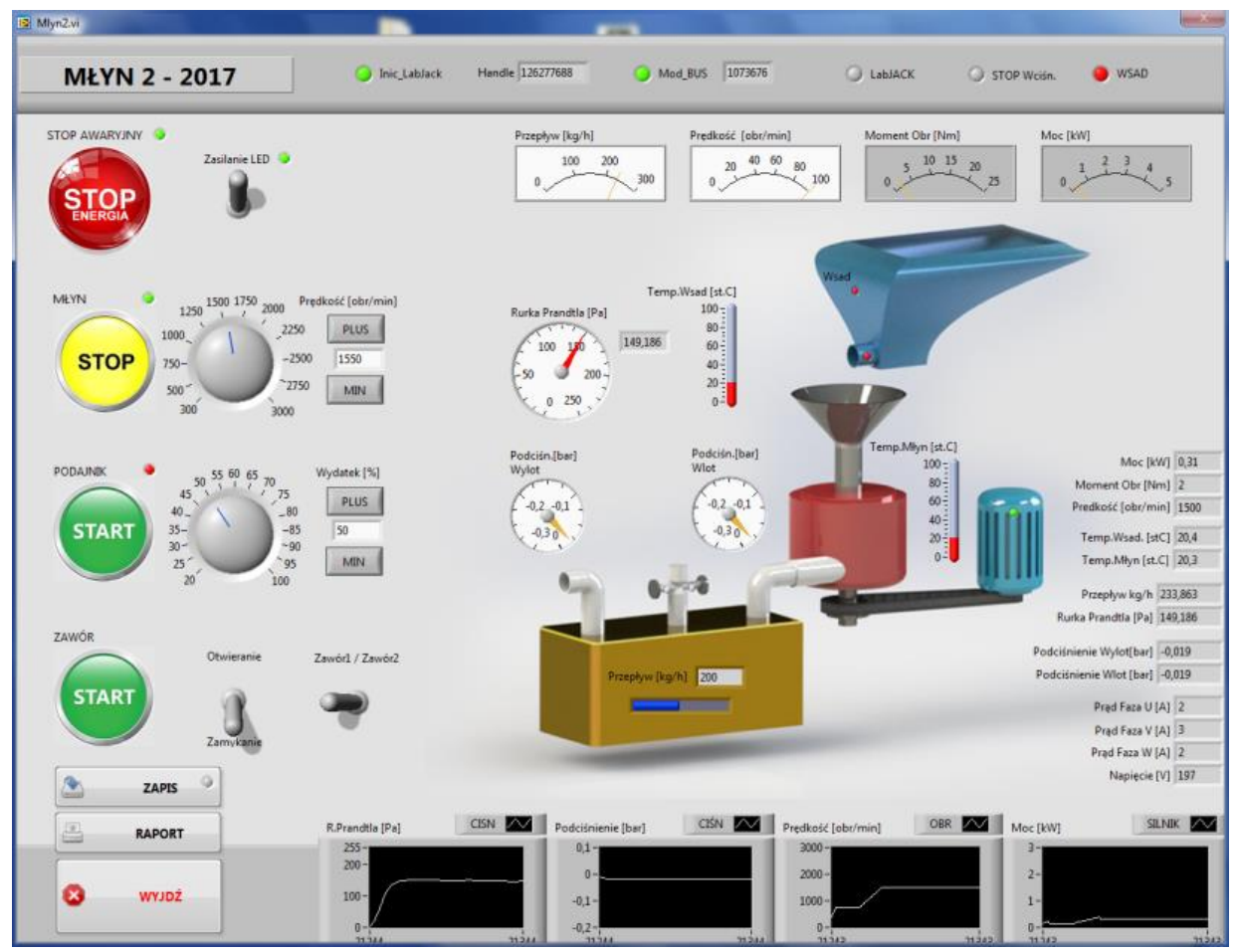

Fig. 3: View on the control panel in the precise grinding test stand. 


\section{Transfer function of system}

Before designing the control system, one should find a mathematical model describing the dynamic properties of the analysed technological line. It was assumed that this model will be a description in the form of a transfer function. Due to the nature of the flow, a theoretical analysis is extremely difficult, so it was assumed that it will be determined on the basis of experimental research. In the first step, the research was carried out in clean atmospheric air, without the material being grinded.

All the elements of the technological line during mathematical modeling were treated as first-order static elements with transport delay, i.e. the transfer function can be written in the form of

$$
G_{i}(s)=\frac{\Delta P_{i}(s)}{R_{i}(s)}=\frac{k_{i} e^{-\tau_{i} s}}{T_{i} s+1} \quad i=(1,2, \ldots, 5)
$$

where: $\Delta P_{i}$ is pressure indicated by the Prandtl probe, $R_{i}$ - hydraulic resistance of the grinding installation, $k_{i}$ - gain, $T_{i}$ - time constant, $\tau_{i}$ - delay time, all for the tested elements.

The elements of the system are connected in series, therefore the transfer transmittance of the entire system is determined by the formula

$$
G(s)=\frac{\Delta P(s)}{R(s)}=\frac{\prod_{i=1}^{4}\left(k_{i}\right) e^{-\sum_{i=1}^{4} \tau_{i} s}}{\prod_{i=1}^{4}\left(T_{i} s+1\right)} \quad i=(1,2, \ldots, 4)
$$

where: $R$-hydraulic resistance of the grinding line. Note that $R$ it is not a simple sum of component resistances because the elements are non-linear and there is interaction between them.

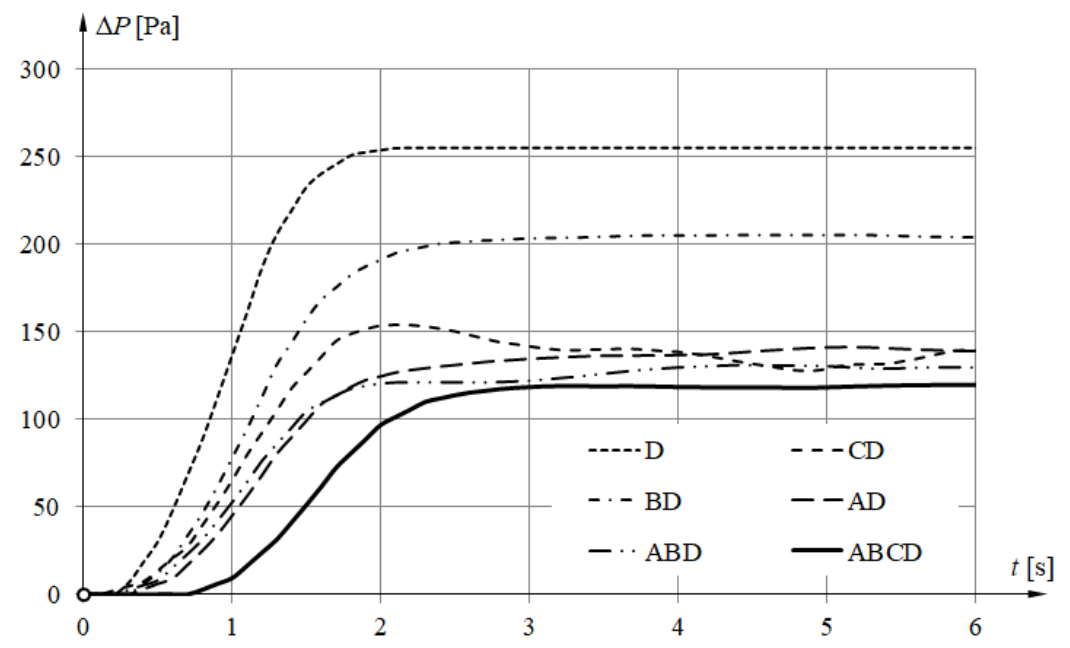

Fig. 4. Transient characteristics of the grinding installation and its selected parts.

The rotor speed control system predicted in the future will be based on the flow velocity measurement in the pipe ahead of the aspirator. It follows that the most important measurement is to test the flow rate through the entire process line (ABCD measurement - Fig. 4). The ABCD curve enables direct determination of the transfer function of the grinding line, Equation (2). The influence of individual line elements on the flow velocity through the tested system was also investigated. An important measurement was determining the properties of the aspirator, because it must be used during other measurements - line D. Connection of the storage vessel has the smallest impact on the properties of the technological line BD line. This is a beneficial phenomenon because during the actual technological process, this element will most significantly change its properties as a result of it being filled with the grinded material.

The transfer function $G(s)$ is approximated by a first-order system with a transport lag as follows

$$
G(s)=\frac{\Delta P(s)}{R(s)}=\frac{\Delta P_{\text {inf }} e^{-\tau_{\mathrm{P}}}}{T_{\mathrm{P}} s+1}=\frac{120.6 e^{-1.05 s}}{1.21 s+1}
$$


Based on the first method Ziegler-Nichols (Ogata, 2010) tuning rules the delay time $\tau_{\mathrm{P}}$ and time constant $T_{\mathrm{P}}$ are determined by drawing a tangent line at the inflection point of the S-shaped curve (measurement D) and determining the intersections of the tangent line with the time axis and line $\Delta P=\Delta P_{\text {inf }}$, as shown in Fig. 5.

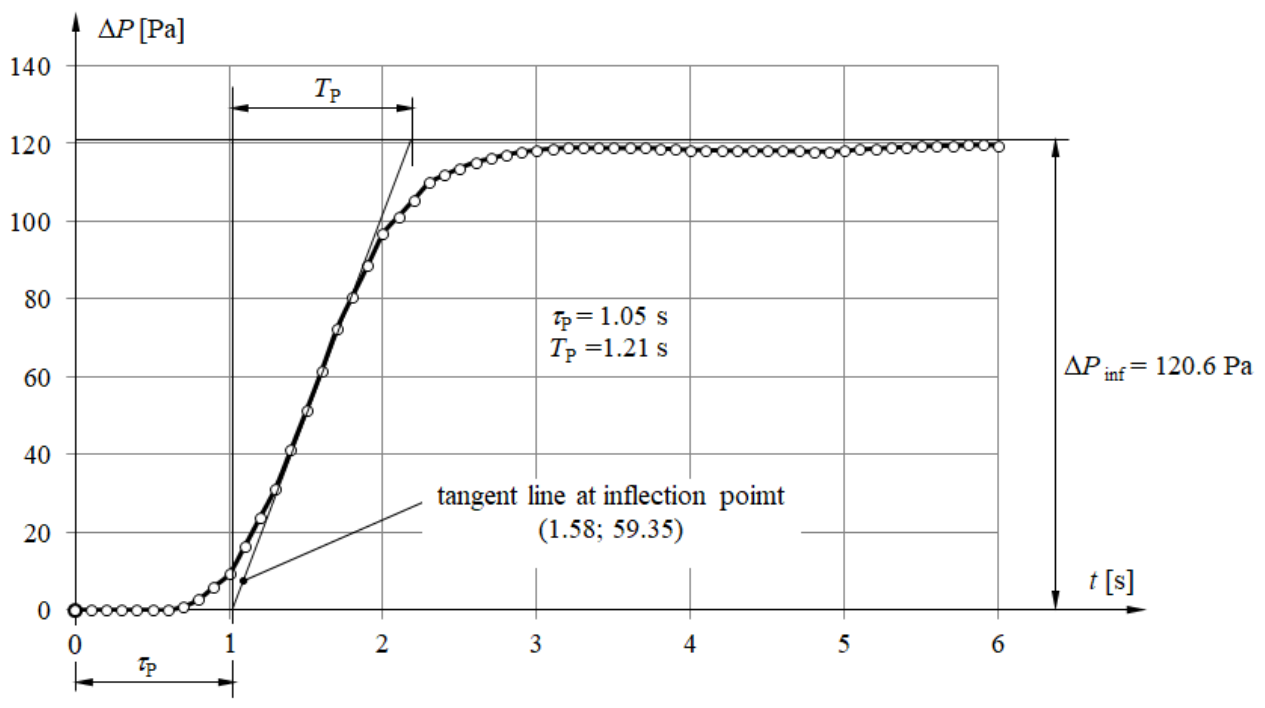

Fig. 5. Dynamic characteristics of technological line.

Therefore, for PID controller proportional gain $K_{\mathrm{P}}=1.2 \frac{T_{\mathrm{P}}}{\tau_{\mathrm{P}}}=1.38$, integral time $T_{\mathrm{i}}=2 \tau_{\mathrm{P}}=2.1 \mathrm{~s}$, and derivative time $T_{\mathrm{d}}=0.5 \tau_{\mathrm{P}}=0.525 \mathrm{~s}$.

\section{Conclusions}

This work presents a stand for precise grinding of small oilseeds. A stream of air is used to transport the seeds. Because the accuracy of the process is strongly dependent on the flow rate, it is proposed to build a flow rate control system based on the measurement of the maximum velocity by the Prandtl probe placed in the axis of the aspirator input pipe. The rotational speed of the aspirator will be adjusted. The transfer function (3) of system found enables a qualitative selection of the PID controller. The authors are aware of the fact that the actual transfer function will have different parameters; however, when designing the control system what matters is only the initial determination of the tuning parameters. These settings can always be improved. The control system is very important due to the variability of the process parameters during the technological line operation.

\section{References}

Czerniak, J., Macko, M., Śmigielski, G., Tyszczuk, K. and Zarzycki, H. (2015) Approach to the Monitoring of Energy Consumption in Eco-grinder Based on ABC Optimization. In: Kozielski S., Mrozek D., Kasprowski P., Małysiak-Mrozek B., Kostrzewa D. (eds) Beyond Databases, Architectures and Structures. BDAS 2015. Communications in Computer and Information Science, Springer, Cham, 521, pp. 516-529.

Macko, M., Flizikowski, J., Szczepański, Z., Tyszczuk, K., Śmigielski, G., Mrozinski, A., Czerniak, J. and Tomporowski, A. (2017) CAD/CAE Applications in Mill's Design and Investigation. In: Rusiński E., Pietrusiak D. (eds) Proceedings of the 13th International Scientific Conference. RESRB 2016. Lecture Notes in Mechanical Engineering. Springer, Cham, pp. 343-351.

Ogata, K. (2010) Modern Control Engineering Fifth Edition, Prentice Hall, ISBN 13: 978-0-13-615673-4

Pecháč, P. and Sága, M. (2016) Controlling of local search methods' parameters in memetic algorithms using the principles of simulated annealing. Proc. Eng., 136, pp. 70-76.

Tyszczuk, K., Jankowski, M. and Kopacz, S. (2009) Algorytm optymalizacji rozdrabniania nasion oleistych z wykorzystaniem programowania genetycznego. Ap. Chem. 48, 2, pp. 54-55.

Tyszczuk, K., Peszyński, K., Mroziński, A. and Śmigielski, G. (2018) Analysis and modeling of variables of the precise shredder's pneumatic material transport's system. Machine Modeling and Simulations 2017 (MMS 2017), MATEC Web Conf., 157, 01020. 